\title{
How to Manage a Project of Citizen Science: Olfactory Annoyance Evaluation in Taranto City (Italy)
}

\author{
M. Brattoli ${ }^{1}$, L. de Gennaro ${ }^{3}$, A. Mazzone ${ }^{1}$, S.Petraccone ${ }^{2}$, A. Demarinis Loiotile ${ }^{2}$, R. Giua ${ }^{1}$, G. \\ Assennato $^{1}$, G. de Gennaro ${ }^{1,2}$ \\ ${ }^{1}$ Agenzia Regionale per la Prevenzione e la Protezione Ambientale Puglia - Corso Trieste 27, 70126 \\ Bari, Italy \\ ${ }^{2}$ Dipartimento di Chimica, Università degli Studi di Bari, via Orabona, 4, 70126 Bari, Italy \\ ${ }^{3}$ Lenviros srl - spin off dell'Università degli Studi di Bari, via degli Antichi Pastifici ZI,70056 Molfetta, \\ Italy \\ annamaria.demarinis@uniba.it
}

\begin{abstract}
Odour annoyance represents one of the most emerging aspects related to odour emissions, produced by industrial plants and constitutes an indicator of an unhealthy environment, strongly felt by population. Odour emission is considered as one of the most important causes of population complaints and its evaluation represents a matter characterized by great complexity. The management of the complaints of the citizens, living in the surroundings of odour sources, represents a very hard topic to face for public authorities. Taranto city, located in the South of Italy, is seriously afflicted by a strong environmental pollution produced by the different plants in the industrial area. In this area a project of citizen science has been applied by means of an experimental methodology for the detection and evaluation of olfactory annoyance, called Odortel $\AA^{\circledR}$; it is able to integrate automatic remote systems in order to record the olfactory perception of human receptors and to collect odour samples in real time. In this project citizens play a key role to alert the public authority by means of a phone switchboard, communicating in real time the perception of odor events and their intensity. The application of Odortel ${ }^{\circledR}$ in the area of Taranto has permitted, for the first time, to manage the population complaints in a systematic way, to prove the refinery as the source and, at the same time, to perform improvements in sampling-analysis process.
\end{abstract}

Key words: odour annoyance, citizen science, odour monitoring, innovative sampling systems, population complaints, dynamic olfactometry

\section{Introduction}

Odour impact constitutes an indicator of an unhealthy environment, strongly felt by population. Even though real risks for human health have not been demonstrated yet, the association between an annoying odour perception and psycho-physical symptoms such as states of anxiety, headache, depression, eye irritation, respiratory problems, nausea, etc., is verified [1-4]. So, odour emission is considered as one of the most important causes of population complaints and its evaluation represents a matter characterized by great complexity, due principally to the strict association of odour pollution to human perception [5]. In fact, the need to establish a causal relation between odour events (often characterized by a brief duration) and odour sources is often problematic. On the other hand, population living in the surroundings of odour sources denounces the occurrence of odour events to the local authorities (municipalities, police, environmental agencies, etc.), that are often overwhelmed by continuous complaints, not easily manageable. Moreover, another aspect to take into account is the evaluation of the reliability of population complaints and how it is possible to make objective these warnings, since, in most cases, these protests are considered the alarm bells to start a monitoring activity.

Some international legislation, above all German one, standardize methods involving directly the population in order to evaluate the olfactory annoyance and define its entity through specific indicators [6,7].

These methods will involve, for instance, the distribution of questionnaires to people living in the surroundings of the emission source [6] or methods of odour evaluation in field using 
selected sniffers who have to evaluate systematically the perception of odour in different fixed positions on the territory at different times every day [7]. The described methodologies are screening qualitative investigations and request long time of study before providing useful information regarding the real entity of odour impact.

In most cases, it is necessary to give prompt answers to population and to this purpose, the opportunity to perform a measurement in real time when citizen perceive the odour is the only one method to provide objectivity to their complaints. Obviously it is a critical aspect, since a variable period of time passes from the signal to the operative intervention of environmental agencies and it can occur that the odour event is often no more verified.

The paper focuses on the management and the application of a citizen science project in Taranto city, in the South of Italy. Nowadays projects that involve citizen scientists are burgeoning, particularly in environmental sciences, although the roots of citizen science go back to the very beginnings of modern science itself [8]. Collaborations between scientists and volunteers have the potential to broaden the scope of research and enhance the ability to collect scientific data [9]. Citizen science includes communitybased monitoring (CBM), "a process where concerned citizens, government agencies, industry, academia, community groups, and local institutions collaborate to monitor, track and respond to issues of common community (environmental) concern" [10].

This article describes a new methodology for the detection and the evaluation of olfactory annoyance, integrating automatic remote systems to record the olfactory perception of human receptors and to collect odour samples in real time.

\section{Materials and methods Site description}

The experimental study has been conducting in the area of Taranto, a city of the South of Italy, seriously afflicted by a strong environmental pollution produced by the different plants in the industrial area. In fact, it constitutes an important pole of steel production (it is located the biggest metallurgic center in Europe) and of petroleum refining. Moreover, there are some other facilities such as a landfill, a cement plant and a military arsenal. All of these industrial sources produce odour emissions and annoyance for the residents living in the area. Figure 1 shows the position of the principal plants on the industrial area of Taranto.

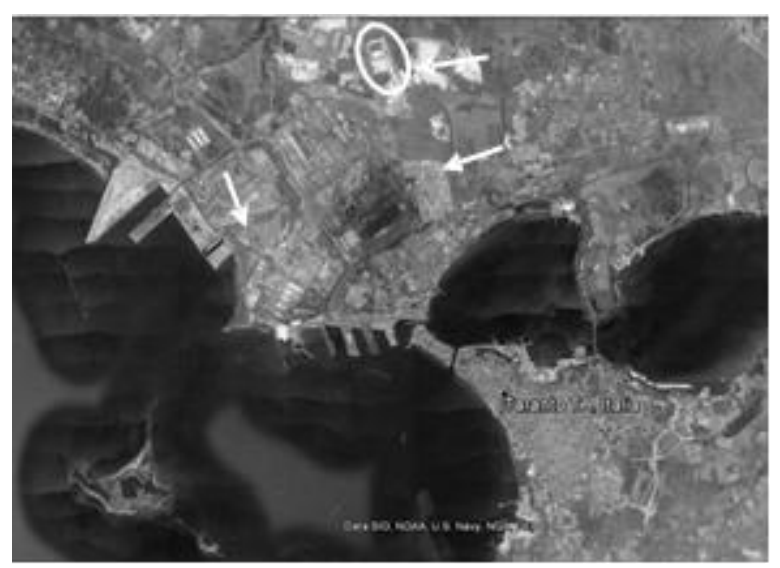

Fig. 1. Map of the city of Taranto.

An innovative experimental methodology to evaluate the odour annoyance perceived by population, called Odortel囚, has been applied in this city, in collaboration with the Regional Environmental Agency of Puglia (ARPA).

\section{The system architecture}

Odortel $\AA$ is able to integrate automatic remote systems in order to record the olfactory perception of human receptors and to collect odour samples in real time.

Odortel囚, realized by Lenviros srl, a spin-off company of the University of Bari, in collaboration with University of Bari and Labservice srl, consists of a telephonic system that systematizes the population complaints and of automatic sampling systems, remotely activable, able to collect air sample in real time, at the moment of the significant odour events. The main features of the approach used are:

- Systemization and digitalization of telephone complaints

- Display of reports on real-time map

- Remotely sampling system in real time

Each citizen (called receptor) is georeferenced on the map and is coded inside the system database. Using a telephone switchboard, the receptor communicates the odour perception and also its intensity (via the telephone keypad), choosing among three level of intensity, visualized with different colors: Faint odour (green color), Persistent odour (yellow color), Very strong odour (red color).

The phone calls are recorded and displayed on the map in real time on a website, accessible from stakeholders through an username and a password. The graphical interface allows to interact with database to obtain information regarding date, time and number of calls in a synoptic visualization or in a graphical one. Figure 2 displays an example of a synoptic daily visualization and the localization of the signals in the map (white points). 

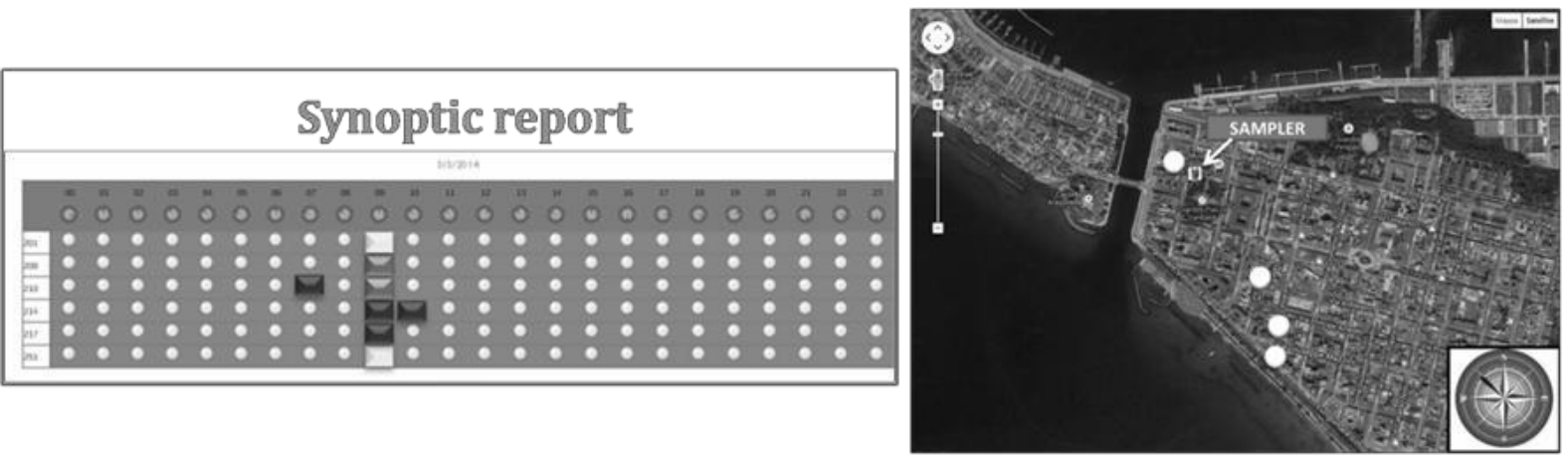

Fig. 2. Example of a synoptic daily visualization and localization of the signals in the map.

The setting of specific routine, based on the number of calls for index of intensity in a period of time, allows to activate remotely sampling systems, depression pumps, located in a representative site. They collect air samples in real time that will be measured by means of dynamic olfactometry, according to the technical law EN 13725/2003.

The olfactometric measurements are carried out by a dynamic olfatometer (series TO8 by Ecoma), employing the yes/no method for the sample presentation.

The information about the pump activation is immediately sent to the technical operators through telephone messages in order to pick up the sample and prepare the olfactometric measurement within 30 hours.

Figure 3 shows the system architecture through a schematic diagram.

The experimental activity in Taranto city, from November 2013, has involved a growing number of citizens (at the moment about 60 receptors) and two automatic remote sampling systems.

\section{Preliminary results}

The temporal distribution of the complaints received highlights that reports of intensity 3 (very strong odor) are the most numerous in the whole period and they occurred just when the receptors were in a position downwind of the industrial zone, thus confirming the reliability of the information given by the population. The data collected have pointed out that residents, living close to the coastal area, have communicated the most copious complaints, as shown in Figure 4. Moreover the olfactometric results, measured in correspondence of the events perceived by receptors, have shown concentration levels significantly higher than those measured for blank samples.
In order to support the evidences shown by the application of Odortel $\circledast$, possible correlations with air quality data (in particular, $\mathrm{H}_{2} \mathrm{~S}$ and sulfur compounds), recorded by monitoring stations, will be investigated.

\section{Conclusions}

The application of Odortelß in the area of Taranto has permitted, for the first time, to manage the population complaints in a systematic way, involving actively themselves in a project of citizen science. An overall scheme that summarizes the logical path of the project is represented in Figure 5.

Through this project, the population of Taranto, exhausted of the environmental conditions of their city, for the first time was engaged in the air quality monitoring issues, playing a valuable role in influencing larger decisions about science policy. Citizen science bridges gaps by harnessing the power of people who are motivated by curiosity, a desire to advance research, or a concern about environmental conditions in their communities, then connecting them to projects that benefit from their energy and dedication.

Citizens living in Taranto city, in this way, have increased their understanding about the process of science and the environmental problems through this engagement in authentic science, in contrast to traditional [11].

The involvement of citizens in Odortel® project allowed to identify and prove the refinery as the source and, at the same time, to perform improvements in sampling-analysis process. The integrated system used in this study proves its effectiveness and its real applicability to complex phenomena, such as odorous, which require innovative methodologies. 


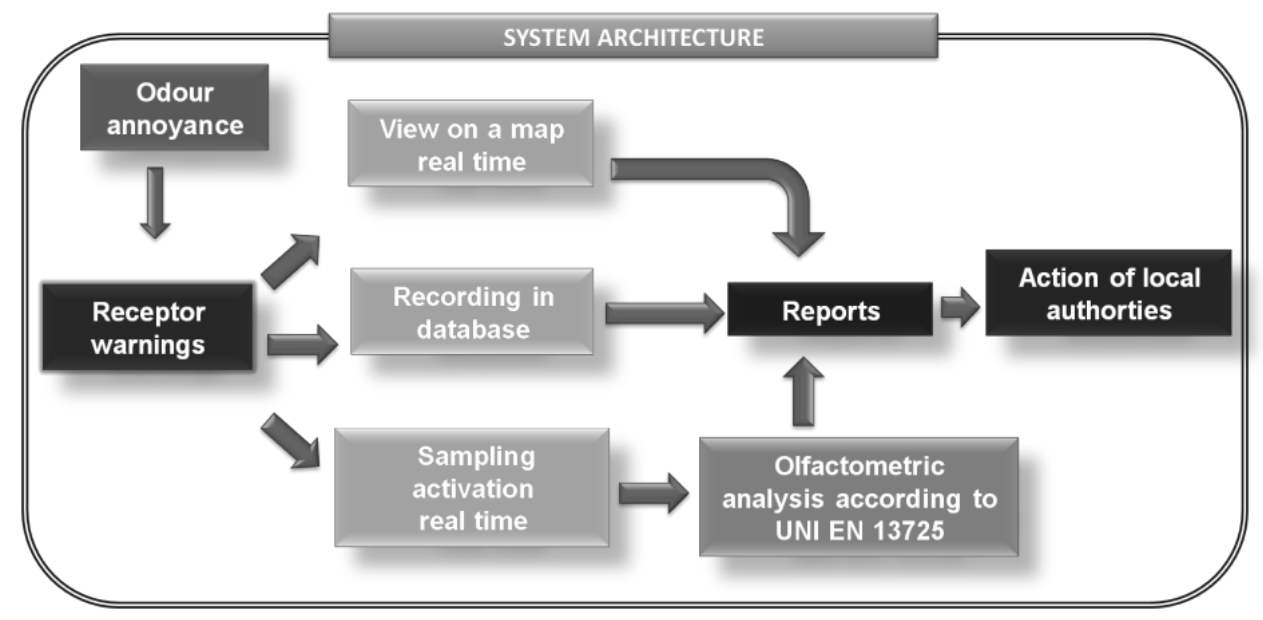

Fig. 3. Schematic diagram related to the system architecture.

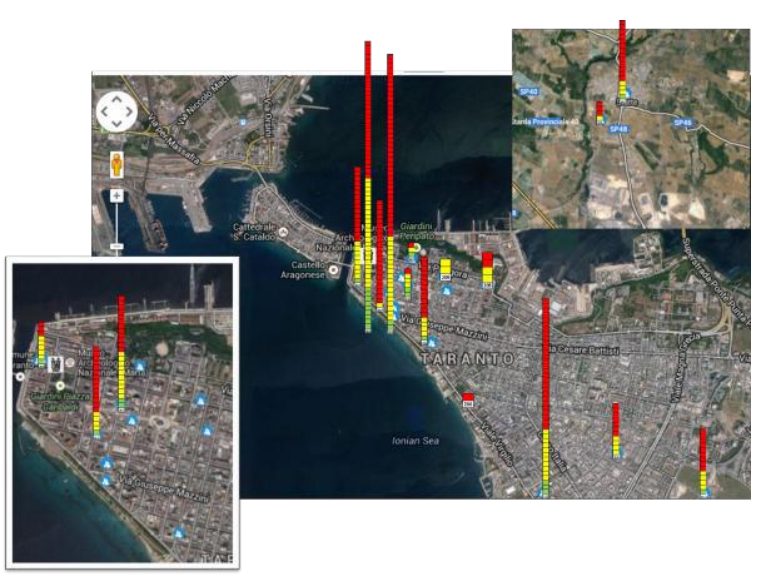

Fig. 4. Spatial distribution of receptor warnings on the territory.

\section{References}

[1] S.S. Schiffman, Livestock odors: Implications for human health and well-being. J. Anim. Sci. 76, 1343-1355 (1998)

[2] K. Sucker, K. Both, G.Winneke, Review of adverse health effects of odours in field studies. Water Sci. Technol. 59, 1281 - 1289 (2009)

[3] T. Stenlund, E. Liden, K. Andresson, J. Garvill, S. Nordin, Annoyance and health symptoms and their influencing factors: a population based air pollution intervention study. Public Health, 123, 339 - 345 (2009)

[4] M. Aatamila, P.K. Verkasalo, M. J. Korhonen, A. L. Suominen, M.R. Hirvonen, M.K. Viluksela, A. Nevalainen, Odour annoyance and physical symptoms among residents living near waste treatment centres. Environmental Research, 111, 164-170 (2011)

[5] M. Brattoli, G. de Gennaro, V. de Pinto, A. Demarinis Loiotile, S. Lovascio, M. Penza, Odour Detection Methods: Olfactometry and Chemical Sensors. Sensors, 11, 5290-5322 (2011)

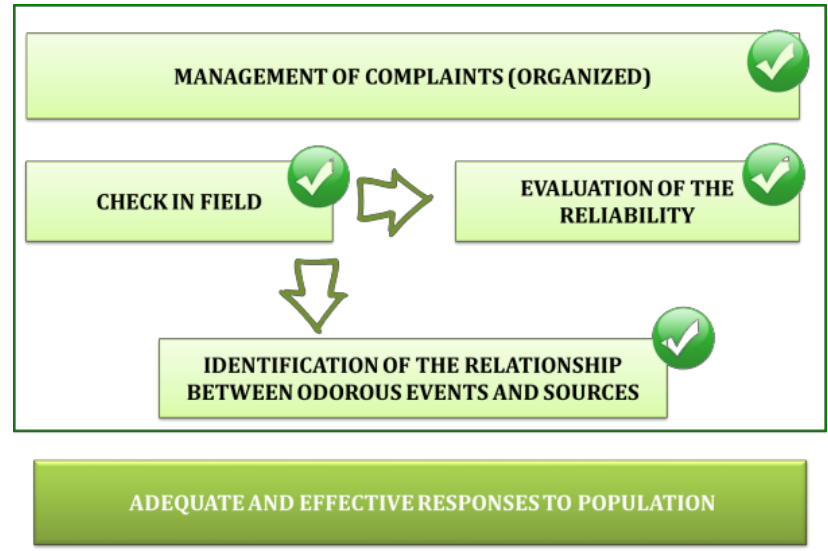

Fig. 5. The logical path of the project.

[6] VDI 3883:1993, Blatt 2, Effects and assessment of odours - Determination of annoyance parameters by questioning, Repeated brief questioning of neighbour panellist, Germany.

[7] VDI 3940:2006, Measurement of odour impact by field inspection - Measurement of the impact frequency of recognizable odours - grid measurements, Germany.

[8] J. Silvertown, A new dawn for citizen science, Trends in Ecology \& Evolution, Volume 24, Issue 9, 467-471 (2009)

[9] Jeffrey P. Cohn, Citizen Science: Can Volunteers Do Real Research? BioScience 58 (3): 192-197 (2008)

[10] G. Whitelaw, H. Vaughan, B. Craig, and D. Atkinson, Establishing the Canadian Community Monitoring Network. Environmental Monitoring and Assessment 88:409-418 (2003)

[11] D.J. Trumbull, R. Bonney, D.Bascom, A. Cabral, Thinking scientifically during participation in a citizen-science project. Science Education, 84, 2, 265-275 (2000) 